\title{
Health status in 1040 adults with disorders of sex development (DSD): a European multicenter study
}

\author{
Henrik Falhammar, ${ }^{1,2}$ Hedi Claahsen-van der Grinten ${ }^{3}$, Nicole Reisch$^{4}$, Jolanta Slowikowska-Hilczer ${ }^{5}$, \\ Anna Nordenström ${ }^{6,7}$, Robert Roehle ${ }^{8}$, Claire Bouvattier ${ }^{9,10}$, Baudewijntje P C Kreukels ${ }^{11}$ and Birgit Köhler ${ }^{12}$ \\ on behalf of the dsd-LIFE group
}

\author{
${ }^{1}$ Department of Endocrinology, Metabolism and Diabetes, Karolinska University Hospital, Stockholm, Sweden \\ ${ }^{2}$ Department of Molecular Medicine and Surgery, Karolinska Institutet, Stockholm, Sweden \\ ${ }^{3}$ Department of Pediatric Endocrine Disease, Radboud University Nijmegen Medical Centre, Nijmegen, The Netherlands \\ ${ }^{4}$ Medizinische Klinik and Poliklinik IV, Department of Endocrinology, University Hospital Munich, Munich, Germany \\ ${ }^{5}$ Department of Andrology and Reproductive Endocrinology, Medical University of Lodz, Lodz, Poland \\ ${ }^{6}$ Department of Women's and Children's Health, Karolinska Institutet, Stockholm, Sweden \\ ${ }^{7}$ Department of Paediatric Endocrinology, Astrid Lindgren Children Hospital, Karolinska University Hospital, Stockholm, Sweden \\ ${ }^{8}$ Coordinating Center for Clinical Studies, Charité Universitätsmedizin, Berlin, Germany \\ ${ }^{9}$ Paris-Sud University, Orsay, France \\ ${ }^{10}$ Department of Pediatric Endocrinology, Hôpital Bicêtre, Assistance Publique-Hôpitaux de Paris, Le Kremlin Bicêtre, France \\ ${ }^{11}$ Department of Medical Psychology, VU University Medical Center, Amsterdam, The Netherlands \\ ${ }^{12}$ Department of Paediatric Endocrinology and Diabetology, Charité Universitätsmedizin, Universitätsmedizin Berlin, corporate member of Freie \\ Universität Berlin, Humboldt-Universität zu Berlin and Berlin Institute of Health, Berlin, Germany
}

Correspondence should be addressed to H Falhammar: henrik.falhammar@ki.se

\section{Abstract}

Objective: The knowledge about health status in adults with disorder of sex development (DSD) is scarce.

Design and methods: A cross-sectional observational study in 14 European tertiary centers recruited 1040 participants (717 females, 311 males, 12 others) with DSD. Mean age was $32.4 \pm 13.6$ year (range 16-75). The cohort was divided into: Turner $(n=301)$, Klinefelter $(n=224), X Y-D S D(n=222), X X-D S D$ (excluding congenital adrenal hyperplasia (CAH) and 46,XX males) ( $n=21), 46, \mathrm{XX}-\mathrm{CAH}(n=226)$ and 45,X/46,XY $(n=45)$. Perceived and objective health statuses were measured and compared to European control data. Results: In DSD, fair to very good general health was reported by $91.4 \%$ and only $8.6 \%$ reported (very) bad general health (controls $94.0 \%$ and $6.0 \%, P<0.0001$ ). Longstanding health issues other than DSD and feeling limited in daily life were reported in $51.0 \%$ and $38.6 \%$, respectively (controls $24.5 \%$ and $13.8 \%, P<0.0001$ both). Any disorder

Key Words
congenital adrenal
hyperplasia
Klinefelter syndrome
- Turner syndrome
- age at diagnosis
- healthy lifestyle
psychiatric
- suicide
- cardiovascular
- cotabolic
except DSD was present in $84.3 \%$ (controls $24.6 \%, P<0.0001$ ). Males reported worse health than females. In the subgroup analysis, Klinefelter and $46, X X-D S D$ patients reported bad general health in $15.7 \%$ and $16.7 \%$, respectively (Turner $3.2 \%$ and CAH $7.4 \%$ ). Comorbidities were prevalent in all DSD subgroups but Klinefelter and Turner were most affected. Early diagnosis of DSD and a healthy lifestyle were associated with less comorbidities.

Conclusions: Overall, general health appeared to be good but a number of medical problems were reported, especially in Klinefelter and Turner. Early diagnosis of DSD and a healthy lifestyle seemed to be important. Lifelong follow-up at specialized centers is necessary.

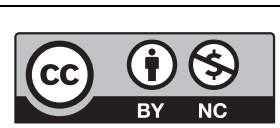

This work is licensed under a Creative Commons Attribution-NonCommercial 4.0 International License. 


\section{Introduction}

Disorders of sex development (DSD) are characterized by incongruence of chromosomal, gonadal and genital sex development, and in some conditions, impaired adrenal function. DSD can be divided into three major groups: DSD with atypical sex chromosome configurations such as Turner syndrome (TS), Klinefelter syndrome (KS), $45, \mathrm{X} / 46, \mathrm{XY}$ and 46,XX/46,XY; XY-DSD characterized by impairment of testicular development, androgen biosynthesis or action or severe hypospadias of unknown origin; and XX-DSD characterized by androgen excess such as congenital adrenal hyperplasia (CAH) (1). Due to the wide range of pathophysiology and presentation, patients with DSD may need a large variety of treatments such as genital surgery, sex hormone replacement, glucocorticoid supplementation and other treatments, which beside the underlying cause also may affect the health status, both somatically and mentally. However, knowledge about the health status in individuals with DSD, especially adults, is scarce. For example, for the rare XY-DSD conditions, almost no data on health status are available except that there is a high prevalence of decreased bone mineral density in CAIS women $(2,3)$. The vast majority of reports have been published on the three larger groups of DSD, namely TS, KS and CAH. These reports have indicated increased risks of congenital abnormalities in TS, cardiometabolic risk factors and diseases mostly related to treatment, autoimmune disorders, tumors and psychiatric disorders in addition to decreased bone health with increased fracture incidence for all groups $(4,5,6,7,8,9,10,11,12,13,14,15,16$, $17,18,19,20,21)$. A healthy lifestyle can modify and prevent many of these comorbidities but how the persons with DSD perceive their general health may differ from the perception of their treating physicians. Moreover, it could be speculated that a late diagnosis of DSD may result in a more compromised health status. Undiagnosed low sex hormone levels during adolescence may affect peak bone mass (3), while high androgen levels may affect voice and insulin sensitivity in females (22). Thus, more data on the health status in individuals with a DSD are needed, including modifying factors, to be able to predict, prevent and manage different health outcomes, in addition to plan specialized services for this group of patients.

The aim of this study was to describe the health status of the whole dsd-LIFE cohort by evaluating comorbidities, cardiovascular and metabolic risk factors, healthy lifestyle and age at diagnosis.

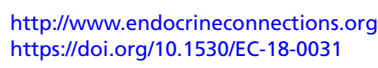

\section{Subjects and methods}

This study is part of the dsd-LIFE study (23). Patients, aged 16 years and older with a medically confirmed clinical and/or genetic diagnosis of DSD, were recruited from 14 sites, including Berlin, Munich, Lubeck and Munster (Germany); Paris, Lyon, Montpellier and Toulouse (France); Amsterdam and Nijmegen (The Netherlands); Lodz and Warsaw (Poland); Stockholm (Sweden) and Birmingham (UK). Control data were obtained from Eurostat (total $n>200,000$; females $n>100,000$; males $n>100,000$, year 2014) (http://ec.europa.eu/eurostat/ web/health/overview), except in five conditions where no data were available, i.e., psychiatric disorders, suicide attempts, hypertension, dyslipidaemia and autoimmune disorders (only thyroid disorders) where controls were obtained from Swedish CAH studies with similar age and gender distribution as the dsd-LIFE study (total $n=58,800$; females $n=33,500$; males $n=25,300)(16,18,24)$.

\section{Study protocol}

The complete study protocol has been published in detail previously by Röhle et al. (23). In summary, subjects underwent a medical examination, including questions about the medical history and answered a patient reported outcome questionnaire. The participation rate was $36.1 \%$ of those contacted, the genetic diagnosis rate was $78.6 \%$ of the total and $55.6 \%$ of those with non-sex chromosome DSD, the patient reported outcome questionnaire response rate was $95.5 \%$, medical history was supplied by $99.5 \%$ and examination was done in $89.2 \%$. Data were entered anonymously into a database. Healthy lifestyle, age at diagnosis, cardiovascular and metabolic risk factors and comorbidity were evaluated. A healthy lifestyle was defined as never smoked in combination with sport activities $\geq 2 \mathrm{~h} /$ week. Participants were asked to rate their general health as good/very good, fair or bad/very bad. For cardiovascular and metabolic risk factors, the following variables were evaluated: body mass index (BMI) (overweight $25-29.9$ and obesity $\geq 30 \mathrm{~kg} / \mathrm{m}^{2}$ ); waist/hip ratio (central obesity $\geq 0.8$ in females and $\geq 0.9$ in males, respectively); hypertension (blood pressure $>140 / 90 \mathrm{mmHg}$ ); type 2 diabetes; dyslipidaemia and cardiovascular disease (history of heart attack, stroke, venous thromboembolism, arrhythmias, coarctation of the aorta, bicuspid aortic valve or aortic stenosis). For the description of comorbidities, the following

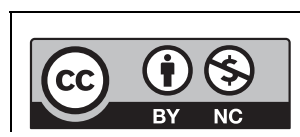

This work is licensed under a Creative Commons Attribution-NonCommercial 4.0 International License. 
variables were used: psychiatric disorders (eating disorder, chronic anxiety, chronic depression, attention problems, hyperactivity, eruptive/aggressive behaviour, burn-out-syndrome, schizophrenia, autism, Asperger or pervasive developmental disorder, other mental health problems and/or suicide attempt); gastrointestinal disorders (fatty liver disease, hepatitis, elevated liver enzymes, Crohn's disease/colitis and/or celiac disease); autoimmune disorders (Hashimoto's thyroiditis, type 1 diabetes, rheumatology disease, Crohn's disease/colitis, celiac disease, allergies and/or asthma); joint problems (rheumatic disease and/or other joint problems); renal disorders (horseshoe kidney and/or renal insufficiency); malignancy; visual and hearing issues; neurological disorders (seizures and/or migraine); urinary issues (urinary tract infections and/or incontinence) and any disorder except DSD was defined as any of the disorders or problems above (except overweight and obesity), calculated with both visual issues included and excluded.

The study was approved by the Local Ethical Review Board at each participating center, and informed consent was obtained (23).

\section{Statistical analysis}

Mean \pm s.D. or median (range) is reported for continuous variables, and absolute and relative frequencies for categorical outcomes. All proportions were calculated discounting missing values. Continuous variables were compared using $t$-tests, and categorical parameters were compared using chi-squared tests or Fisher exact tests, whichever most appropriate. Logistic regression models were used to explore the associations between different outcomes and age at diagnosis and healthy lifestyle. When odds ratios (ORs) were calculated, 95\% confidence intervals (CIs) were reported. Due to the exploratory nature of dsd-LIFE, no adjustments for multiple comparisons were done. $\mathrm{R}$ (version 3.2.2) and SAS (version 9.4) were used for all statistical analyses.

\section{Results}

The results are shown in detail for the total cohort and for phenotypic females and males in Tables 1 and 2, broken down by subgroup in Tables 3 and 4 and logistic regression models in Table 5. In Supplementary Table 1 (see section on supplementary data given at the end of this article), the number of individuals for each variable is shown.

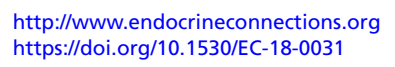

\section{Basic characteristics of the patients}

In total, 1161 patients were evaluated in dsd-LIFE cohort, but males with CAH $(n=121)$ were excluded in the present analyses since they did not fulfill the complete criteria for a DSD diagnosis (23). Thus, 1040 patients were included with a mean age range of $32.4 \pm 13$.6 years. The different DSD diagnoses and the six major subgroups of the cohort are described in Table 1. One 47,XYY male was not included in any of the subgroups. The number of females was more than twice the number of males and the mean age about 4 years younger in females. Moreover, the mean age at diagnosis of the DSD condition was 8 years earlier in females (Table 2).

\section{Lifestyle and general health}

Around $15 \%$ in the whole DSD cohort was currently smoking, which was less than controls (Table 2). None of the XX-DSD individuals and only around $7 \%$ of individuals with TS or 45,X/46,XY smoked (Table 3). Sport activities per week, varied in the different groups and differed from controls. Especially the XY-DSD males seemed to be very active (Table 4 ). Of the entire cohort $91.4 \%$ reported a fair to good/very good general health and only $8.6 \%$ reported bad or very bad general health, which was worse compared to controls. Males with DSD reported worse health compared to females with DSD $(15.2 \%$ vs $5.6 \%)$. General health was worse compared to controls in all subgroups except in XY-DSD females, XX-DSD and 45,X/46XY. Longstanding health issues other than the DSD diagnosis were reported in about half the cohort with physical issues being most common. This was more than that in controls in all groups except XY-DSD males and XX-DSD. In general, males had more physical and psychiatric problems than females. Individuals with KS reported most longstanding health problems (62.4\%). Almost half of all males felt limited in their daily life by health issues and the KS group was the subgroup that experienced the most limitations while only around $14 \%$ of controls reported limitations. The composite endpoint 'Any disorder except DSD' was present in $84.3 \%$ of all cases, and in $94.5 \%$ of individuals with TS. Similar percentages were found when visual issues were excluded. This was 2-3 times more than those in controls.

\section{Cardiovascular and metabolic disorders}

Mean BMI was $25.5 \mathrm{~kg} / \mathrm{m}^{2}$ in the entire cohort and $17.2 \%$ were obese (controls 14.8\%). Males were more often

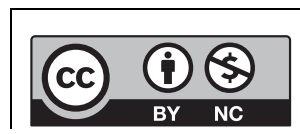

This work is licensed under a Creative Commons Attribution-NonCommercial 4.0 International License. 
Table 1 The specific diagnoses of the 1040 patients with DSD, their subgroup classification and sex.

\begin{tabular}{|c|c|c|c|c|}
\hline & Females & Males & Other & Total \\
\hline Turner syndrome & & & & 301 \\
\hline Monosomy: 45,X & 150 & & & \\
\hline Mosaics: $45, X / 46, X X$ & 31 & & & \\
\hline Isochromosomes: 45,X/46,X,i(Xq)|46X,i(Xq)|45,X/46,X,i(Xq)/47,X,i(Xq) & 59 & & & \\
\hline Deletions: $45, X / 46, X, \operatorname{del}(X) \mid 46, X, \operatorname{del}(X)$ & 19 & & & \\
\hline Polyploidy: 45,X/46,XX/47,XXX|45,X/47,XXX|45,X/46,XX/47,XXX/48,XXXX & 16 & & & \\
\hline Ring material: $45, X / 46, X, r(X)$ & 12 & & & \\
\hline Others and unknown & 14 & & & \\
\hline Klinefelter syndrome & & & & 224 \\
\hline $47, X X Y$ & $1 *$ & 199 & 4 & \\
\hline $47, X X Y / 46, X Y$ & & 5 & 1 & \\
\hline $47, X X Y / 46, X X$ & & 3 & & \\
\hline Others and unknown & & 5 & & \\
\hline $46, X X$ testicular males & & 6 & & \\
\hline XY-DSD & & & & 222 \\
\hline Partial gonadal dysgenesis & 12 & 25 & & \\
\hline XY ovotesticular DSD & 3 & 2 & & \\
\hline CAIS & 69 & & 2 & \\
\hline PAIS & 17 & 18 & & \\
\hline $3 \beta$-HSD deficiency & 1 & 1 & & \\
\hline $17 \beta$-HSD deficiency & 9 & & 2 & \\
\hline $5 \alpha$-reductase deficiency & 2 & 1 & 1 & \\
\hline $17 \alpha$-hydroxylase/17,20 lyase deficiency & 1 & & & \\
\hline Unknown steroid synthesis defect with adrenal insufficiency & 1 & & & \\
\hline Unknown androgen synthesis defect & & 1 & & \\
\hline Hypospadias & & 24 & 1 & \\
\hline Others and unknown & 7 & 1 & & \\
\hline$X X-D S D$ & & & & 21 \\
\hline XX gonadal dysgenesis & 20 & & & \\
\hline XX ovotesticular DSD & 1 & & & \\
\hline Simple virilising $210 H D * * *$ & 65 & $1 * *$ & & \\
\hline Non-classical 210HD*** & 33 & $1 * *$ & & \\
\hline Unknown phenotype 210HD & 3 & & & \\
\hline STAR & 1 & & & \\
\hline 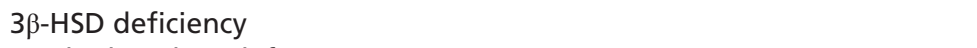 & 2 & & & \\
\hline 11ß-hydroxylase deficiency & 5 & $1 * *$ & & \\
\hline POR deficiency & 2 & & & \\
\hline Unknown & 1 & & & \\
\hline $45, X / 46, X Y$ & 31 & 14 & & 45 \\
\hline $47, X Y Y$ with gonadal dysgenesis & & 1 & & 1 \\
\hline Total & 717 & 311 & 12 & 1040 \\
\hline
\end{tabular}

Males with $46, \mathrm{XY}$-CAH were excluded $(n=121)$ since they did not fulfil all criteria of DSD. STAR, CAH caused by mutations in the steroidogenic acute regulatory protein gene, i.e., congenital lipoid adrenal hyperplasia.

* Had sex reassignment in adulthood; $* * 46, \mathrm{XX} ; * * *$ Mainly based on the predicted phenotype from genotype data.

21OHD, 21-hydroxylase deficiency; CAH, congenital adrenal hyperplasia; CAIS, complete androgen insensitivity syndrome; HSD, hydroxysteroid dehydrogenase; PAIS, partial androgen insensitivity syndrome; POR, cytochrome P450 oxidoreductase.

overweight and almost $60 \%$ of KS patients were either overweight or obese (male controls 54.8\%) (Tables 2 and 3). More than $50 \%$ of the $\mathrm{CAH}$ patients were overweight or obese (38.8\% female controls). However, the proportion of individuals with underweight $\left(\mathrm{BMI}<20 \mathrm{~kg} / \mathrm{m}^{2}\right.$ ) was also higher in the DSD groups compared to controls. Using the different waist/hip ratio cut-off levels for females and males indicated that the health risk in females with DSD was higher, especially in the XX-DSD subgroup. Type 2 diabetes was present in $4.1 \%$ of all patients and was more prevalent in the male group (6.9\%), which was higher than that in controls $(1.7 \%)$. There were large differences

$$
\begin{array}{lr}
\text { http://www.endocrineconnections.org } & \odot 2018 \text { The authors } \\
\text { https://doi.org/10.1530/EC-18-0031 } & \text { Published by Bioscientifica Ltd }
\end{array}
$$

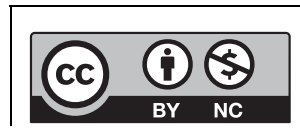

This work is licensed under a Creative Commons Attribution-NonCommercial 4.0 International License. 
in the prevalence of type 2 diabetes between the subgroups with $9.1 \%$ affected in the KS and only $1.5 \%$ in the XY-DSD subgroup. Hypertension was more prevalent compared to controls except in the XY-DSD female and XX-DSD groups. Dyslipidemia was more common compared to controls in all groups except in the XX-DSD. Dyslipidemia was especially prevalent in individuals with KS (19.9\%). Around $15 \%$ of DSD had at least one cardiovascular disease (controls 5\%), 3.1\% two and $0.8 \%$ had three or more diagnoses with no differences between females and males. In the subgroups, cardiovascular disease was especially prevalent in the TS group, $45, \mathrm{X} / 46, \mathrm{XY}$ and KS groups; however, the only subgroup with no increase compared to controls were phenotypically females with XY-DSD or XX-DSD.

\section{Other comorbidity}

Psychiatric disorders were reported in $45.2 \%$ and suicide attempt in $6.8 \%$ of all individuals with DSD and more males than females were affected (Table 2). Especially individuals with KS were affected, but all groups were more affected compared to controls (Tables 3 and 4). The prevalence of osteoporosis and fractures were similar between females and males, however, also here, individuals with KS were most affected. Gastrointestinal disorders were more prevalent in females with DSD overall and in TS (more compared to controls in most groups). Autoimmune disorders were present in a third of the entire DSD cohort (TS $45.2 \%$ and KS $43.3 \%$ ) and equally common in both females and males, which was more than those in controls. Joint problems were more common in males with DSD overall and in KS. Renal disorders were most prevalent in females with DSD overall and in TS, mainly due to congenital horseshoe kidney in the latter. Malignancy had occurred in $4.1 \%$ and was more common than in controls in all groups except XY-DSD males, XX-DSD and 45,X/46,XY. Visual and hearing issues were prevalent, and most affected were patients with TS. Neurological disorders, i.e., seizures and/or migraine were most frequent in KS. Urinary issues were not different between the sexes, but $\mathrm{XY}$-DSD and CAH were the most affected subgroups (no control data).

\section{Logistic regression models}

Using logistic regression models, there were significant associations between any long-standing health problem, health issues that limited daily life, any disorder except DSD and age at diagnosis of the DSD (Table 5). Similar relationships were also found with healthy lifestyle. There was only a tendency for obesity and age at diagnosis but an association was found with healthy lifestyle (OR 0.32). However, there was a positive correlation with age at diagnosis and BMI $(R=0.03$ per year, $P<0.0001)$. Type 2 diabetes, hypertension and dyslipidemia were associated with the age at diagnosis (OR 1.05, 1.03 and 1.04 , respectively). Thus, a diagnosis of DSD at 10 years or 40 years compared to at birth increased the odds for type 2 diabetes with 63\% (OR 1.63) and 604\% (OR 7.04), respectively. Type 2 diabetes and dyslipidemia were less common with a healthy lifestyle (OR 0.20 and 0.62, respectively). Cardiovascular disease was associated with the age at diagnosis (OR 1.03) but not healthy lifestyle. Psychiatric, autoimmune and neurological disorders (OR $1.02,1.02$ and 1.03 , respectively), joint and urinary issues (OR 1.03 and 0.96, respectively) were all associated with age at diagnosis. Among these disorders, healthy lifestyle was only associated with psychiatric disorders (OR 0.29). Similar results were found for the different subgroups and age at diagnosis and healthy lifestyle, respectively, but mostly not significant (data not shown). However, there was a relationship between age at diagnosis and age at inclusion in dsd-LIFE (Fig. 1) explaining some (28.8\%) but not all outcomes related to age at diagnosis $(R=0.537$, $P<0.0001)$.

\section{Discussion}

This is by far the largest study examining the health status in individuals diagnosed with DSD but also the first to include the majority of conditions encompassed by the DSD classification. The patients reported a good or fair general health in more than $91 \%$ of the cases and less than $9 \%$ reported bad or very bad general health. In general, males reported worse health than females but both males and females reported poorer health compared to European control data. Longstanding health issues other than DSD were reported by half of the individuals with men more often reporting both physical and psychiatric comorbidities compared to women. However, if all the different disorders, other than DSD, reported by the individuals themselves or the examining physicians were assessed together more than $80 \%$ had at least one additional comorbidity, which was 2-3 times more common than for controls. Thus, individuals with DSD 


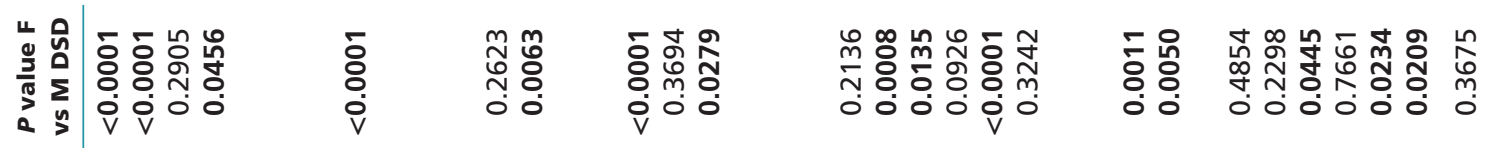

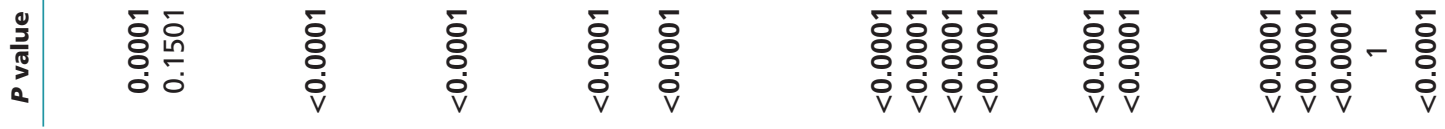

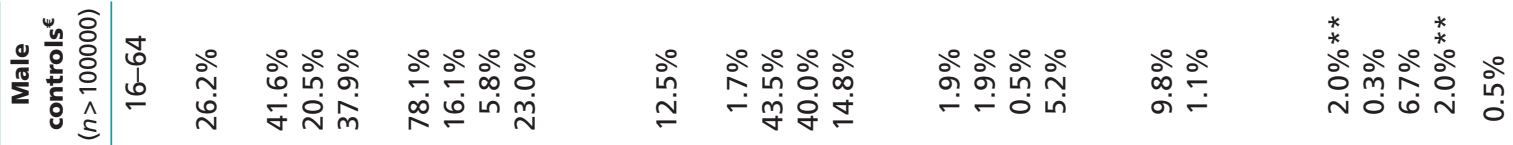

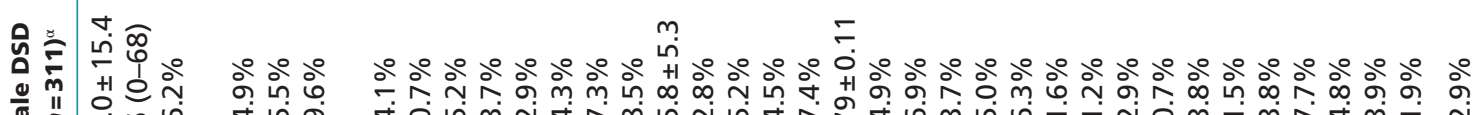

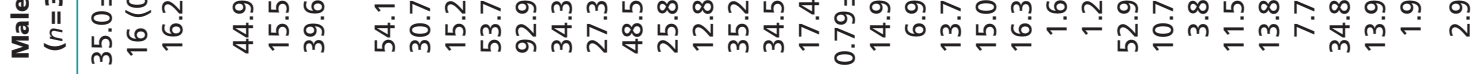

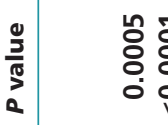
$\begin{array}{ll}\bar{o} & \bar{o} \\ \dot{0} & 0 \\ \dot{0} & \mathrm{O}\end{array}$
$\begin{array}{ll}\bar{o} & \overline{0} \\ \dot{0} & 0 \\ \dot{0} & 0\end{array}$

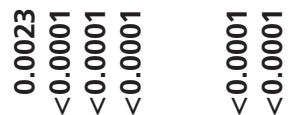

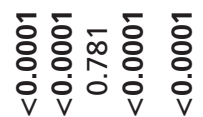

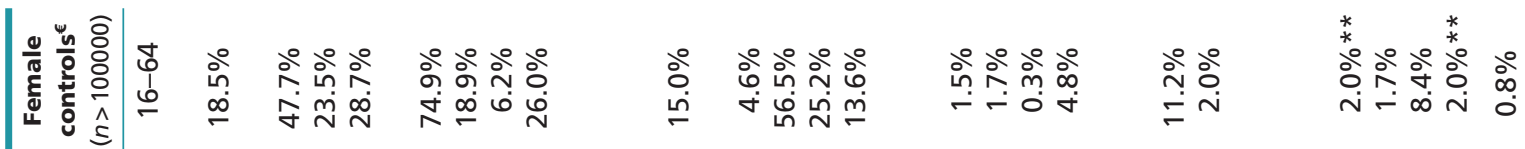

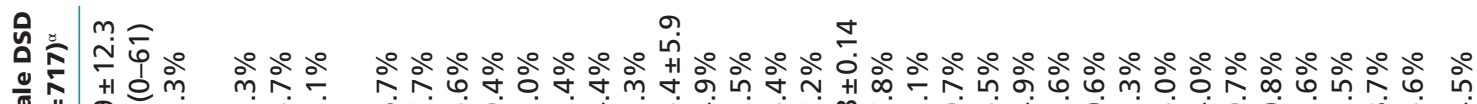
悉

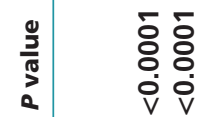
$\begin{array}{ll}\bar{o} & \bar{o} \\ \dot{\mathrm{v}} & \dot{0} \\ \dot{\mathrm{v}} & \mathrm{v}\end{array}$
$\begin{array}{ll}\bar{\delta} & \overline{0} \\ \grave{0} & 0 \\ \dot{0} & 0\end{array}$

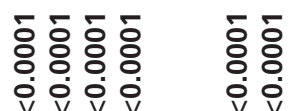

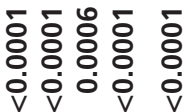

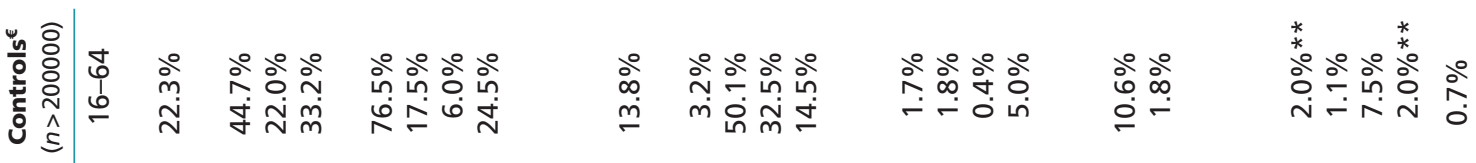

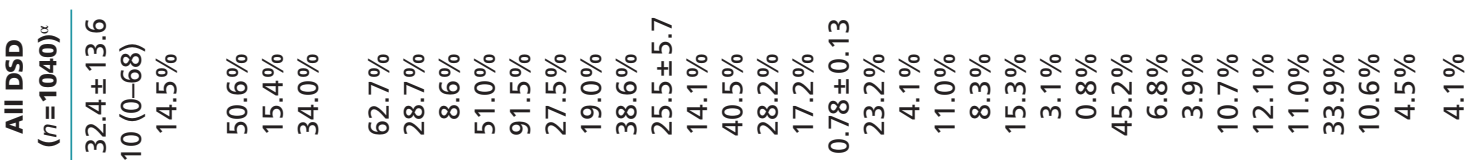

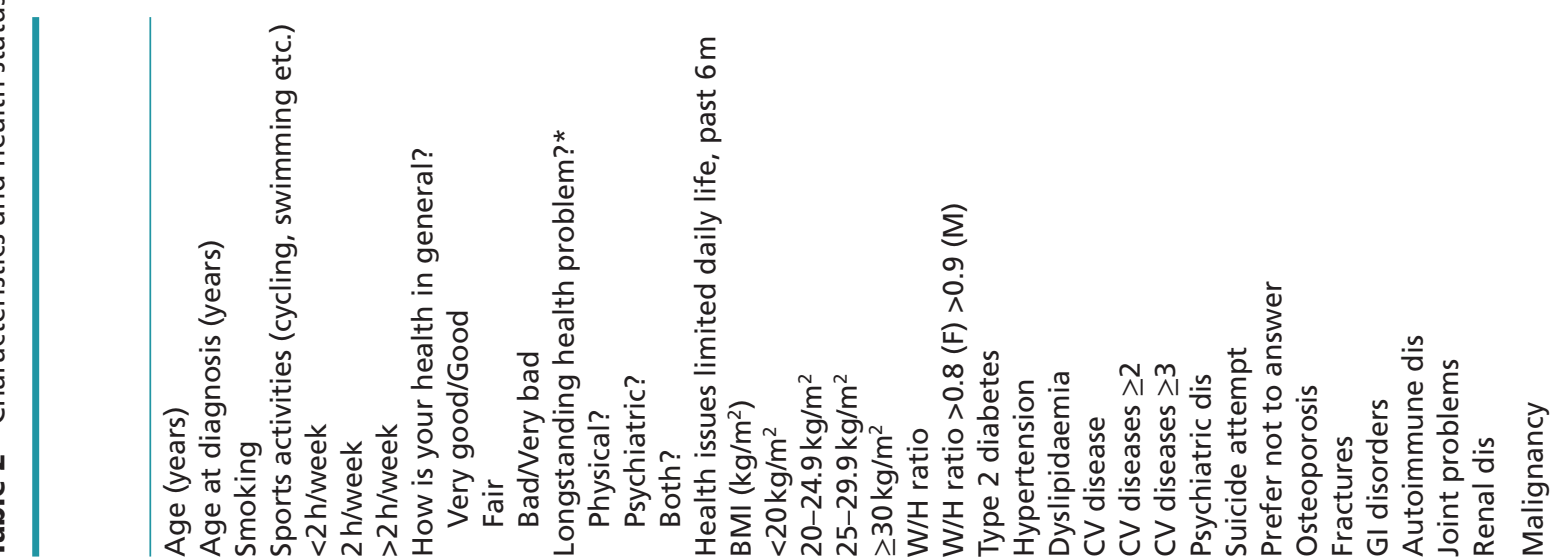

http://www.endocrineconnections.org https://doi.org/10.1530/EC-18-0031
() 2018 The authors Published by Bioscientifica Ltd

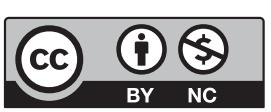

This work is licensed under a Creative Commons Attribution-NonCommercial 4.0 International License. 


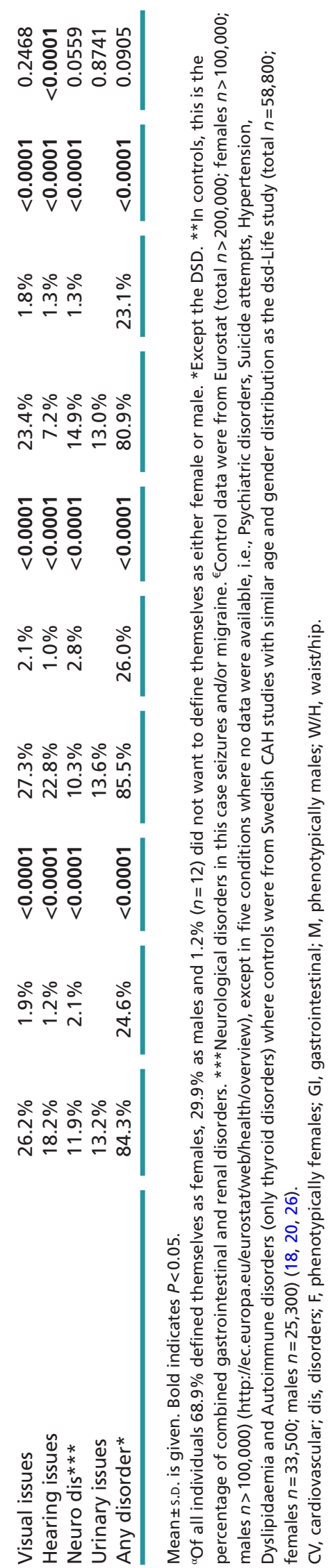

http://www.endocrineconnections.org https://doi.org/10.1530/EC-18-0031
() 2018 The authors Published by Bioscientifica Ltd did not consider many of their comorbidities as major concerns. The finding that less than $40 \%$ responded that health issues had limited their daily life also supports this conclusion.

Cardiovascular and metabolic disorders were common in our cohort, which have previously been shown separately in TS, KS and CAH $(5,7,16)$. It has been suggested that TS is an independent risk factor for cardiovascular disease leading to congenital heart disease, aortic dilation and dissection, valvular heart disease, hypertension, thromboembolism, myocardial infarction and stroke (5). Even though TS had the highest frequency of cardiovascular disease in our study, the frequency was almost as high in the group of $45, \mathrm{X} / 46, \mathrm{XY}$ followed by the KS group. However, women with TS are often affected by congenital heart disease not seen in, e.g., KS and CAH $(7,16)$. A study of 16 children with $45, \mathrm{X} / 46, \mathrm{XY}$ found increased risk of cardiac anomalies and other features of TS, and thus, recommended that $45, \mathrm{X} / 46, \mathrm{XY}$ patients should have similar follow-up (25). However, our study suggests that all different DSD variants (except XY-DSD females and XX-DSD) may have increased cardiometabolic issues to some degree and should be monitored and treated accordingly.

Psychiatric disorders were prevalent, especially in KS. Similar rates have previously been reported in KS (7) and increased rates, however, not as high as in this study have also been reported in CAH $(18,24)$. The high rate of suicide attempts is of great concern. Moreover, some individuals (3.9\%) preferred not to answer this question, which may for some, reflect that they had made a suicide attempt previously but did not want to disclose this or that they had had suicidal thoughts. Suicide and attempts have hardly been studied previously in DSD. In a Swedish registry study, females with $\mathrm{CAH}$ had a lower suicidal rate than the controls ( $0.9 \%$ vs $2 \%)(18)$, while in males with $\mathrm{CAH}$, the rate was higher than in controls $(2.8 \%$ vs $1.2 \%)(24)$, thus, much lower than the $6 \%$ found among the individuals with $\mathrm{CAH}$ in the present study. Probably this reflects that the current study reports on self-reported suicidality while the previous registry studies gave diagnosis rates.

Reported osteoporosis and fractures were rather common despite the young age of the cohort. Especially individuals with TS and KS were affected, which has previously been attributed mainly to hypogonadism and also to X-chromosome abnormalities $(4,7)$. This needs to be investigated in more detail in future studies. In $\mathrm{CAH}$, the use of glucocorticoids may further increase the risk (22), but in the present study, individuals with

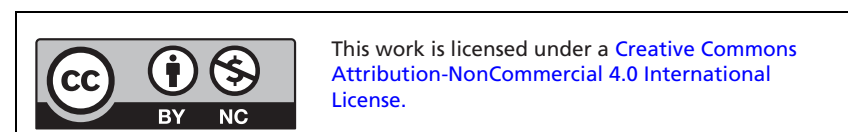


CONNECTIONS

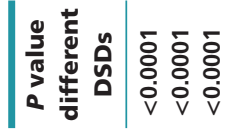
ธัँे 웅

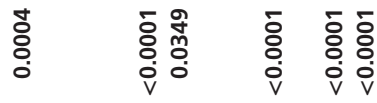

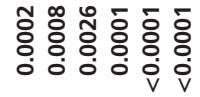
姾各

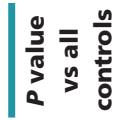

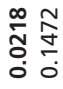

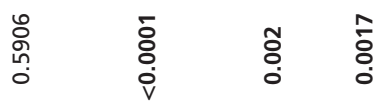

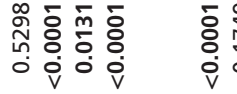

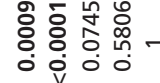

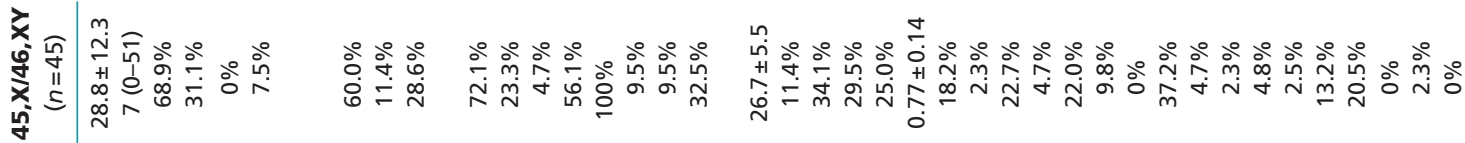

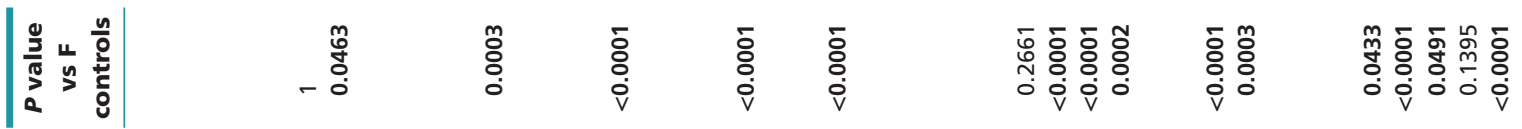

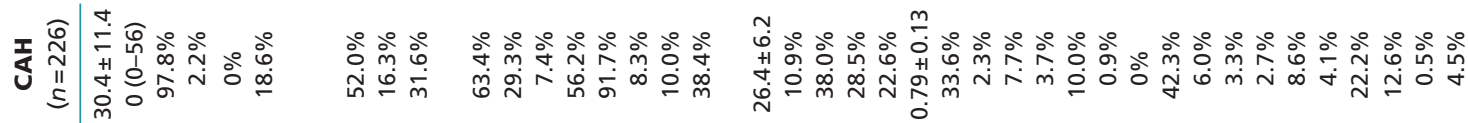

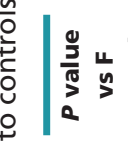

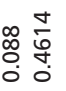

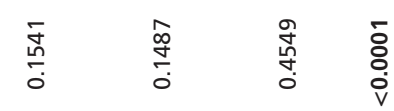

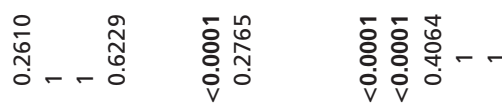

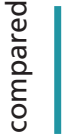

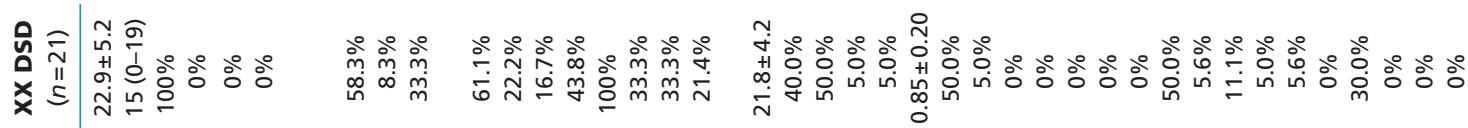

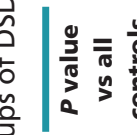

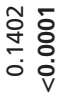

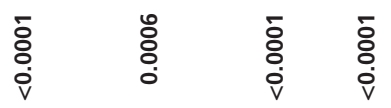

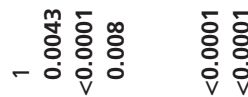

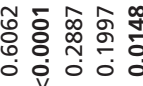

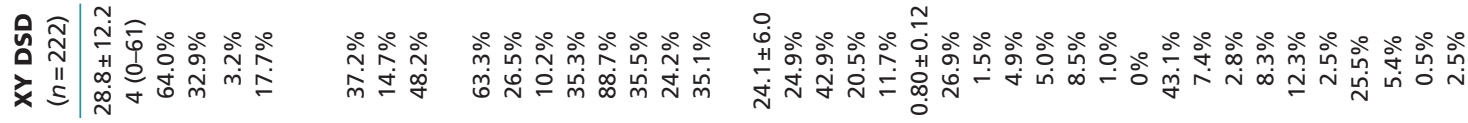

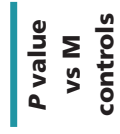

商

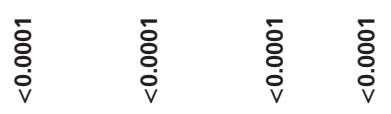

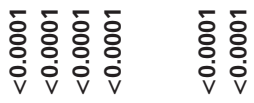

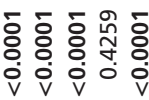

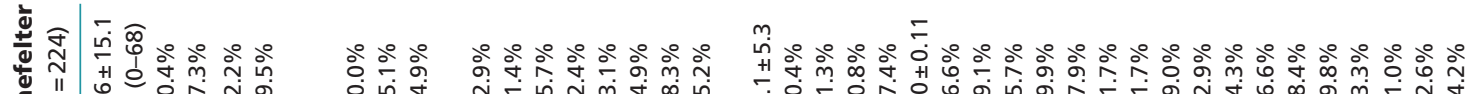

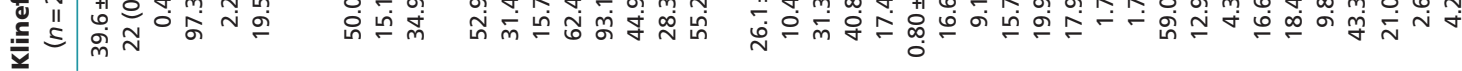

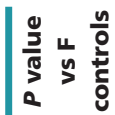

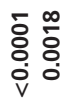

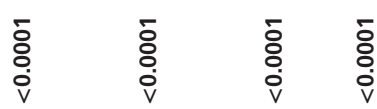

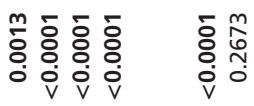

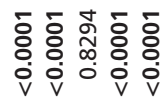

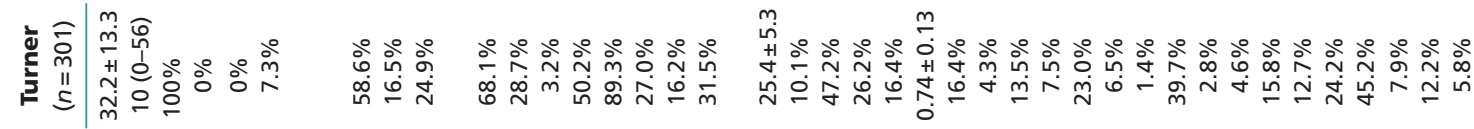
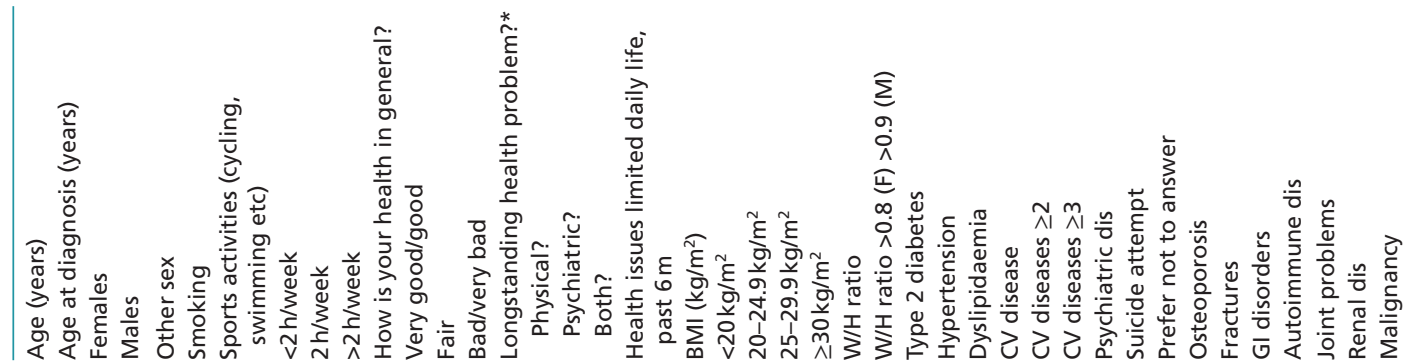

http://www.endocrineconnections.org

(c) 2018 The authors Published by Bioscientifica Ltd

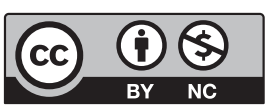

This work is licensed under a Creative Commons Attribution-NonCommercial 4.0 International License. 


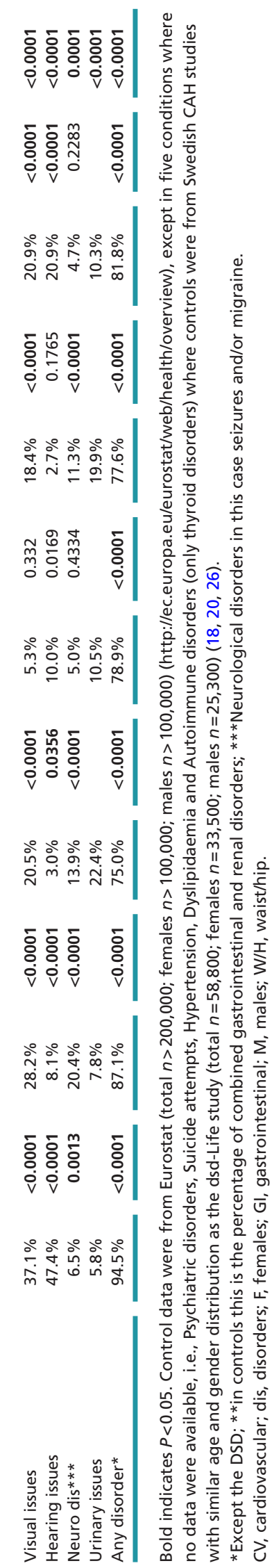

http://www.endocrineconnections.org https://doi.org/10.1530/EC-18-0031
C 2018 The authors Published by Bioscientifica Ltd
$\mathrm{CAH}$ were least affected by osteoporosis. However, the fracture rate in $\mathrm{CAH}$ was three times higher than the osteoporosis rate. A similar pattern has been seen before in females with CAH (9) and may be due to their interest in rough sport and outdoor activities (26). Since most studies of bone mineral density and fractures in different variants of DSD have occurred in young individuals, it can be predicted that this will be an increasing issue with age.

There have been concerns about tumor risk in DSD, especially increased risk for germ cell tumors if Y-chromosome material is present (however not in KS) (27); breast and lung cancer in addition to non-Hodgkin lymphoma in KS $(7,27)$; meningioma and childhood brain tumors and possibly bladder cancer, melanoma and corpus uteri cancer in TS (6). We found an increased risk of malignancies. Since some of the gonads may have been removed during early childhood, the patient and physician may not be aware of the histological report; this may be an underestimation.

Most of the other results concerning comorbidities were as expected, for example, an increased risk of gastrointestinal and autoimmune disorders, horseshoe kidneys, visual and hearing issues in TS (5) and many of the individuals in the XY-DSD and CAH groups had had previous genital surgery and had more urinary issues. Neurological disorders (mainly migraine) and joint problems were especially prevalent in KS but also generally in the whole cohort compared to controls.

In particular, in our cohort, the patients with KS reported the worst outcome. They frequently reported bad general health and longstanding health problems, including most comorbidities. It is not uncommon that KS is undiagnosed, in an epidemiological study, only $25 \%$ of the expected number of patients was diagnosed, and few were diagnosed before puberty (28). This could imply that the identified patients may be those that are more affected by their disorder or have contracted other disorders or comorbidities. Hence, there is a risk for a selection bias and overrepresentation of individuals with KS with more somatic and psychiatric difficulties in this study. On the other hand, a late diagnosis of KS could also at least partly explain the impaired health status vide infra. Interestingly, women with TS had also many disorders such as cardiovascular disorders, renal disorders, in particular horse kidneys and gastrointestinal disorders, i.e. celiac disease, known features of the syndrome, but they still reported better general health, less general health issues and limitations by the disorder than did individuals with KS.

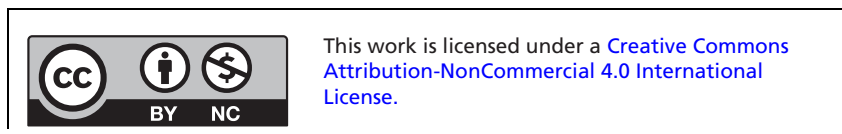


Table 4 Characteristics and health status in the individuals diagnosed with XY DSD divided into phenotypical females and males compared to controls.

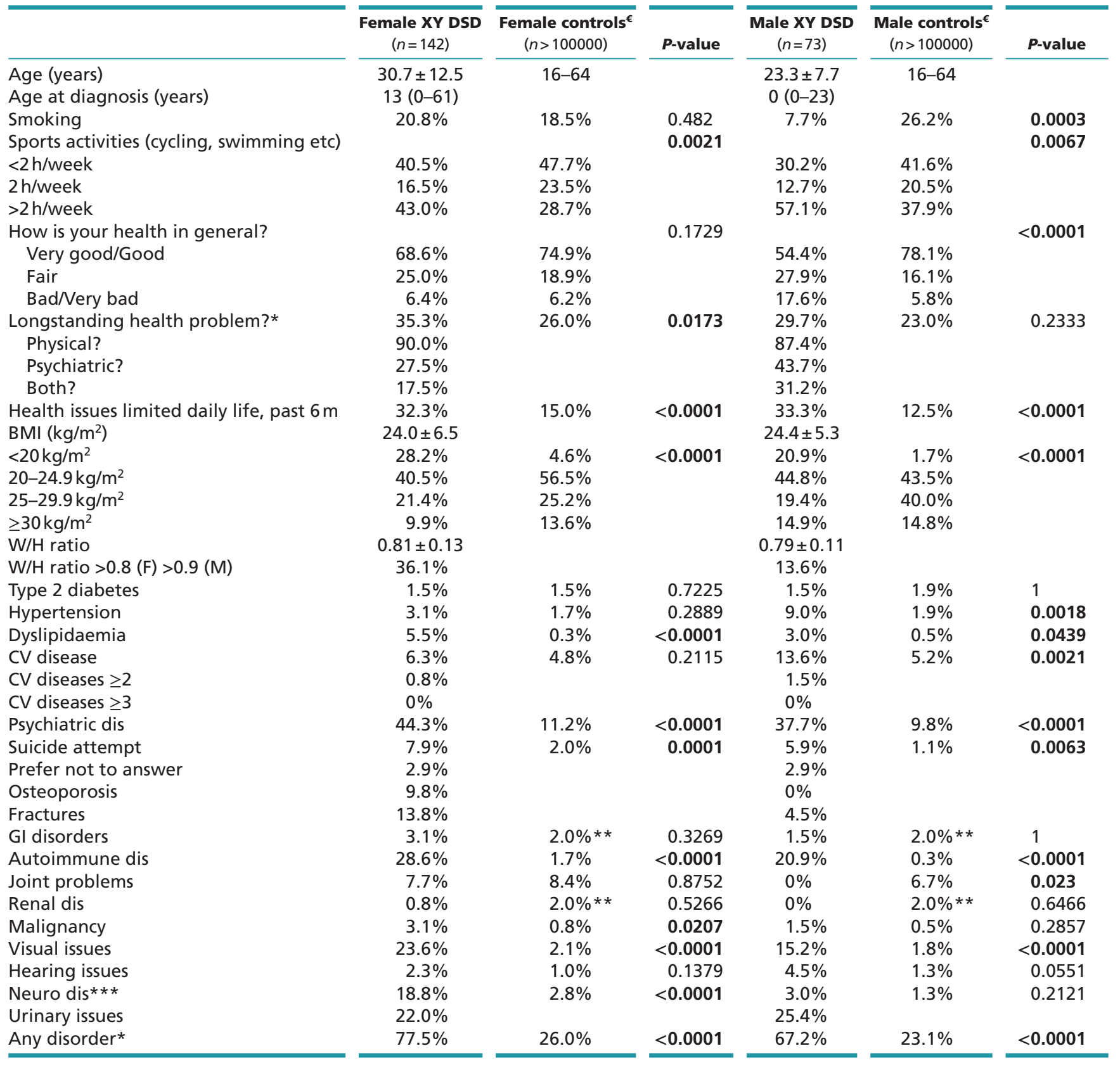

Mean \pm S.D. is given. Bold indicates $P<0.05$.

*Except the DSD; **In controls this is the percentage of combined gastrointestinal and renal disorders; ***Neurological disorders in this case seizures and/or migraine. ${ }^{€}$ Control data were from Eurostat (females $n>100,000$; males $n>100,000$ ) (http://ec.europa.eu/eurostat/web/health/overview), except in five conditions where no data were available, i.e., psychiatric disorders, suicide attempts, hypertension, dyslipidaemia and autoimmune disorders (only thyroid disorders) where controls were from Swedish CAH studies with similar age and gender distribution as the dsd-Life study (total $n=58,800$; females $n=33,500$; males $n=25,300)(18,20,26)$.

CV, cardiovascular; dis, disorders; GI, gastrointestinal; W/H, waist/hip.

The individuals that reported a healthy lifestyle had a reduced risk of developing psychiatric disorders and also as expected a reduced risk of obesity, type 2 diabetes and dyslipidemia. However, a diagnosis of DSD at an older age was associated with an increase of most health issues. There was also a relationship between age

$$
\begin{array}{lr}
\text { http://www.endocrineconnections.org } & \odot 2018 \text { The authors } \\
\text { https://doi.org/10.1530/EC-18-0031 } & \text { Published by Bioscientifica Ltd }
\end{array}
$$

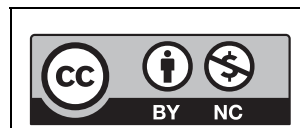

This work is licensed under a Creative Commons Attribution-NonCommercial 4.0 International License. 
Table 5 Logistic regression models exploring associations between different outcomes and age at diagnosis and healthy lifestyle (never smoked and sports activities $\geq 2 \mathrm{~h} /$ week) in patients with DSD.

\begin{tabular}{|c|c|c|c|c|}
\hline & \multicolumn{2}{|c|}{ Age at diagnosis } & \multicolumn{2}{|c|}{ Healthy lifestyle } \\
\hline & OR $(95 \% \mathrm{Cl})$ & $P$ value & OR $(95 \% \mathrm{Cl})$ & $P$ value \\
\hline Longstanding health problem?* & $1.04(1.02-1.05)$ & $<0.0001$ & $0.47(0.20-1.09)$ & 0.0853 \\
\hline Health issues limited daily life, past $6 \mathrm{~m}$ & $1.04(1.03-1.06)$ & $<0.0001$ & $0.68(0.29-1.61)$ & 0.3702 \\
\hline Obesity & $1.01(1.00-1.03)$ & 0.06782 & $0.32(0.12-0.87)$ & 0.0199 \\
\hline Type 2 diabetes & $1.05(1.03-1.08)$ & 0.0002 & $0.20(0.05-0.81)$ & 0.0214 \\
\hline Hypertension & $1.03(1.02-1.04)$ & 0.0003 & $0.71(0.22-2.81)$ & 0.8245 \\
\hline Dyslipidaemia & $1.05(1.02-1.07)$ & $<0.0001$ & $0.62(0.41-0.92)$ & 0.0192 \\
\hline CV disease & $1.03(1.01-1.03)$ & $<0.0001$ & $0.87(0.58-1.27)$ & 0.4728 \\
\hline Psychiatric disorders & $1.02(1.00-1.03)$ & 0.0119 & $0.29(0.12-0.66)$ & 0.0033 \\
\hline Osteoporosis & $1.06(1.04-1.08)$ & $<0.0001$ & $1.64(0.39-11.39)$ & 0.5460 \\
\hline Fractures & $1.04(1.02-1.05)$ & $<0.0001$ & $0.80(0.30-2.40)$ & 0.6710 \\
\hline Autoimmune disorders & $1.02(1.01-1.03)$ & 0.0064 & $1.08(0.47-2.64)$ & 0.9763 \\
\hline Joint problems & $1.03(1.01-1.05)$ & 0.0046 & $0.85(0.23-4.20)$ & 0.7008 \\
\hline Visual issues & $1.01(1.00-1.03)$ & 0.0565 & $5.69(1.62-36.11)$ & 0.0207 \\
\hline Hearing issues & $1.01(0.99-1.02)$ & 0.2777 & $0.39(0.16-1.00)$ & 0.0469 \\
\hline Neurological disorders & $1.02(1.00-1.04)$ & 0.0287 & $0.51(0.16-2.00)$ & 0.1153 \\
\hline Urinary issues & $0.96(0.94-0.98)$ & 0.0006 & $0.55(0.18-2.08)$ & 0.3289 \\
\hline Any disorder* & $1.04(1.02-1.06)$ & 0.0002 & $0.31(0.07-0.93)$ & 0.0003 \\
\hline
\end{tabular}

The higher OR the higher risk per each year later the DSD diagnosis was made. Healthy lifestyle was compared to those with not having a healthy lifestyle. Bold indicates $P<0.05$. No associations were found with waist/hip ratio, suicide attempts, renal and gastrointestinal disorders or malignancy (except females with age at diagnosis $1.04(1.01-1.08), P=0.0057)$ (not shown).

*Except the DSD.

$\mathrm{CV}$, cardiovascular; OR, odds ratio.

at diagnosis of DSD and age at inclusion in the study, but this could only explain a third of the increased risks. A late diagnosis could perhaps be explained by some presenting with their complications and the DSD diagnosis was made simultaneously. The increased risk of different comorbidities with age at diagnosis persisted, however, mostly non-significant when analyzed in the subgroups probably due to the smaller number of individuals. To be diagnosed as early as possible is important in order for management and information to be commenced promptly. This may reduce the risk of future comorbidities. Neonatal screening has already been implemented for CAH in many countries (29) and has been suggested for KS (7). Future studies have to explore if more diagnoses should be included into the neonatal screening programs.

This study has several limitations. Even though we were able to recruit a large number of participants, most were individuals with TS, KS or CAH while it was more difficult to include participants with XY-DSD conditions, partly because those conditions are rarer. There may also have been a selection bias since the participating centers represented many of the most specialized ones in Europe. The questionnaires were constructed in such a way that details of the co-morbidities may not have been captured. There was missing data since the participants could choose not to answer a question or do an examination. Controls were not recruited at the participating centers but large control data were obtained from Eurostat and previous published studies with similar ages, however, not exactly the same age, time period and geographical areas. However, the strengths of this study were that we were able to recruit the highest number of individuals with DSD so far, including some rare variants, and many perspectives of health were examined.

In conclusion, general health seemed good overall in individuals with DSD. However, many medical problems were reported, especially in KS, with a clear increased risk for both somatic and psychiatric morbidities in individuals who were diagnosed later. Knowledge on the specific health issues that might occur in the different diagnoses should be included in the patient education programs, especially during transition. The DSD expert centers have to tailor follow-up programs according to the needs of the individuals and the different diagnostic groups. Therefore, lifelong follow-up by multidisciplinary teams is necessary.

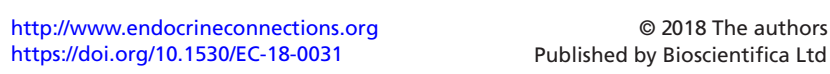




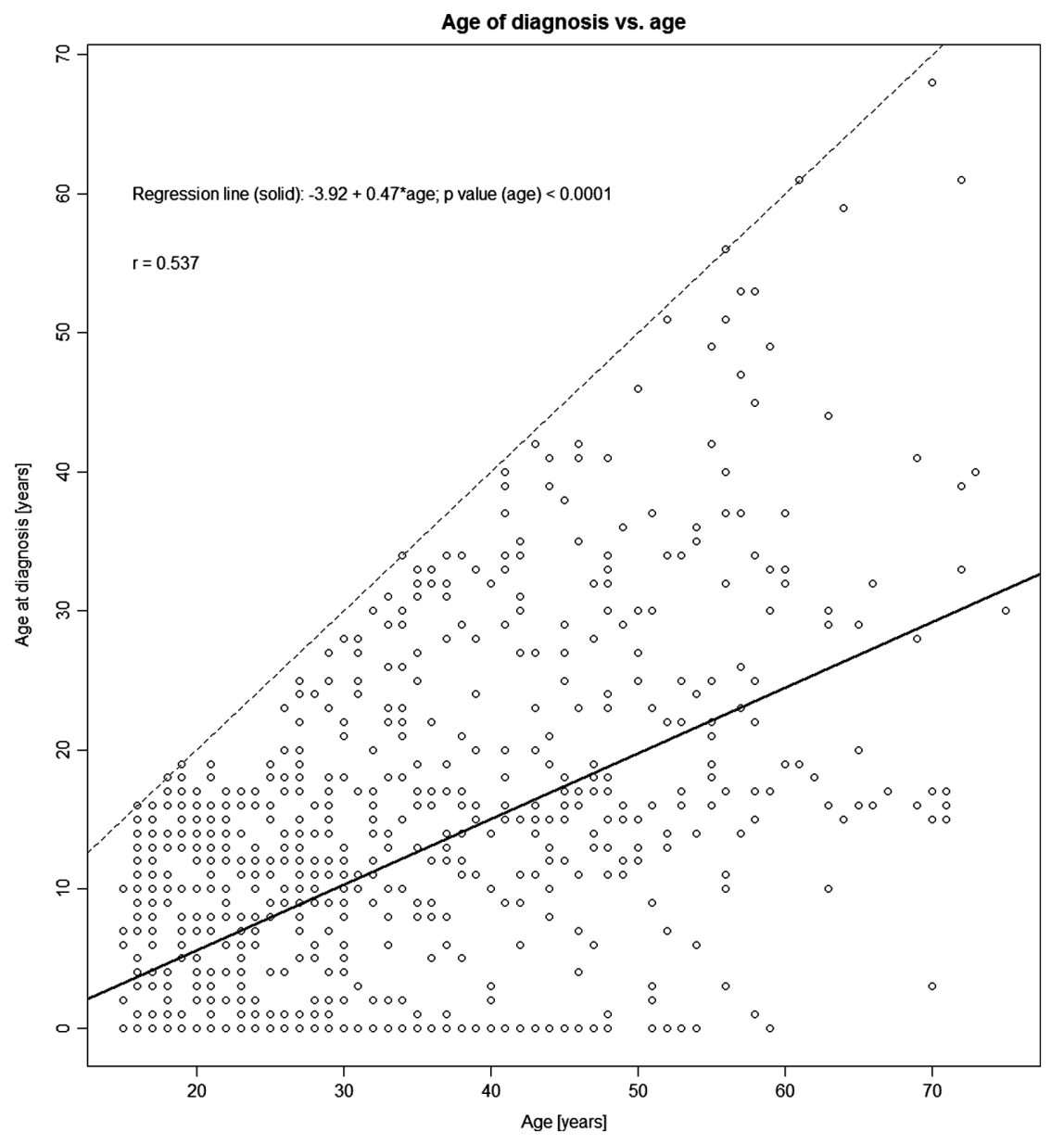

Figure 1

Relationship between age at diagnosis of DSD and age at inclusion in dsd-LIFE study.

\section{Supplementary data}

This is linked to the online version of the paper at https://doi.org/10.1530/ EC-18-0031.

\section{Declaration of interest}

The authors declare that there is no conflict of interest that could be perceived as prejudicing the impartiality of the research reported.

\section{Funding}

This work was supported by the European Union Seventh Framework Programme (FP7/2007-2013) under grant agreement no 305373 (all authors), Karolinska Institutet and Stockholm county council (H F and A N), Magnus Bergvalls Stiftelse (H F), Else Kröner-Fresenius-Stiftung (Grant 2011-EKMS.21; to N R), the European Community (Marie Curie European Reintegration Grant PERG-GA-2010-268270; to N R), Polish Ministry of Science and Higher Education (Grant no 2922/7.PR/2013/2; to J S H).

\section{Acknowledgement}

The dsd-LIFE group is: Birgit Köhler, Berlin; Peggy Cohen-Kettenis and Annelou de Vries, Amsterdam; Wiebke Arlt, Birmingham and Claudia Wiesemann, Gottingen; Jolanta Slowikowska-Hilczer, Lodz; Aude Brac de la Perriere, Lyon; Charles Sultan and Francoise Paris, Montpellier; Claire Bouvattier, Paris; Ute Thyen, Lubeck; Nicole Reisch, Munich; Annette Richter-Unruh, Munster; Hedi Claahsen-van der Grinten, Nijmegen; Anna
Nordenström, Stockholm; Catherine Pienkowski, Toulouse; and Maria Szarras-Czapnik, Warsaw.

\section{References}

1 Lee PA, Houk CP, Ahmed SF, Hughes IA, International Consensus Conference on Intersex organized by the Lawson Wilkins Pediatric Endocrine Society \& the European Society for Paediatric Endocrinology. Consensus statement on management of intersex disorders. International Consensus Conference on Intersex. Pediatrics 2006118 e488-e500. (https://doi.org/10.1542/peds.20060738)

2 Han TS, Goswami D, Trikudanathan S, Creighton SM \& Conway GS. Comparison of bone mineral density and body proportions between women with complete androgen insensitivity syndrome and women with gonadal dysgenesis. European Journal of Endocrinology 2008159 179-185. (https://doi.org/10.1530/EJE-08-0166)

3 Bertelloni S, Baroncelli GI \& Mora S. Bone health in disorders of sex differentiation. Sexual Development 20104 270-284. (https://doi. org/10.1159/000315961)

4 Faienza MF, Ventura A, Colucci S, Cavallo L, Grano M \& Brunetti G. Bone fragility in Turner syndrome: mechanisms and prevention strategies. Frontiers in Endocrinology 20167 34. (https://doi. org/10.3389/fendo.2016.00034)

5 Mortensen KH, Andersen NH \& Gravholt CH. Cardiovascular phenotype in Turner syndrome - integrating cardiology, genetics, and endocrinology. Endocrine Reviews 201233 677-714. (https://doi. org/10.1210/er.2011-1059)

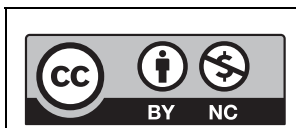

This work is licensed under a Creative Commons Attribution-NonCommercial 4.0 International License. 
6 Schoemaker MJ, Swerdlow AJ, Higgins CD, Wright AF, Jacobs PA \& Group UKCC. Cancer incidence in women with Turner syndrome in Great Britain: a national cohort study. Lancet Oncology 20089 239-246. (https://doi.org/10.1016/S1470-2045(08)70033-0)

7 Groth KA, Skakkebaek A, Host C, Gravholt CH \& Bojesen A. Clinical review: Klinefelter syndrome - a clinical update. Journal of Clinical Endocrinology and Metabolism 201398 20-30. (https://doi. org/10.1210/jc.2012-2382)

8 Falhammar H, Filipsson H, Holmdahl G, Janson PO, Nordenskjold A, Hagenfeldt K \& Thoren M. Metabolic profile and body composition in adult women with congenital adrenal hyperplasia due to 21-hydroxylase deficiency. Journal of Clinical Endocrinology and Metabolism 200792 110-116. (https://doi.org/10.1210/jc.2006-1350)

9 Falhammar H, Filipsson H, Holmdahl G, Janson PO, Nordenskjold A, Hagenfeldt $\mathrm{K} \&$ Thoren $\mathrm{M}$. Fractures and bone mineral density in adult women with 21-hydroxylase deficiency. Journal of Clinical Endocrinology and Metabolism 200792 4643-4649. (https://doi. org/10.1210/jc.2007-0744)

10 Arlt W, Willis DS, Wild SH, Krone N, Doherty EJ, Hahner S, Han TS, Carroll PV, Conway GS, Rees DA, et al. Health status of adults with congenital adrenal hyperplasia: a cohort study of 203 patients. Journal of Clinical Endocrinology and Metabolism 201095 5110-5121. (https://doi.org/10.1210/jc.2010-0917)

11 Reisch N, Scherr M, Flade L, Bidlingmaier M, Schwarz HP, MullerLisse U, Reincke M, Quinkler M \& Beuschlein F. Total adrenal volume but not testicular adrenal rest tumor volume is associated with hormonal control in patients with 21-hydroxylase deficiency. Journal of Clinical Endocrinology and Metabolism 201095 2065-2072. (https:// doi.org/10.1210/jc.2009-1929)

12 Finkielstain GP, Kim MS, Sinaii N, Nishitani M, Van Ryzin C, Hill SC, Reynolds JC, Hanna RM \& Merke DP. Clinical characteristics of a cohort of 244 patients with congenital adrenal hyperplasia. Journal of Clinical Endocrinology and Metabolism 201297 4429-4438. (https:// doi.org/10.1210/jc.2012-2102)

13 Falhammar H, Nystrom HF, Ekstrom U, Granberg S, Wedell A \& Thoren M. Fertility, sexuality and testicular adrenal rest tumors in adult males with congenital adrenal hyperplasia. European Journal of Endocrinology 2012166 441-449. (https://doi.org/10.1530/EJE-11-0828)

14 Falhammar H, Frisen L, Norrby C, Hirschberg AL, Almqvist C, Nordenskjold A \& Nordenstrom A. Increased mortality in patients with congenital adrenal hyperplasia due to 21-hydroxylase deficiency. Journal of Clinical Endocrinology and Metabolism 201499 E2715-E2721. (https://doi.org/10.1210/jc.2014-2957)

15 Bouvattier C, Esterle L, Renoult-Pierre P, de la Perriere AB, Illouz F, Kerlan V, Pascal-Vigneron V, Drui D, Christin-Maitre S, Galland F, et al. Clinical outcome, hormonal status, gonadotrope axis, and testicular function in 219 adult men born with classic 21-hydroxylase deficiency. A French National Survey. Journal of Clinical Endocrinology and Metabolism 2015100 2303-2313. (https:// doi.org/10.1210/jc.2014-4124)

16 Falhammar H, Frisen L, Hirschberg AL, Norrby C, Almqvist C, Nordenskjold A \& Nordenstrom A. Increased cardiovascular and metabolic morbidity in patients with 21-hydroxylase deficiency: a Swedish population-based National Cohort Study. Journal of Clinical Endocrinology and Metabolism 2015100 3520-3528. (https://doi. org/10.1210/JC.2015-2093)

17 Smeets EE, Span PN, van Herwaarden AE, Wevers RA, Hermus AR, Sweep FC \& Claahsen-van der Grinten HL. Molecular characterization of testicular adrenal rest tumors in congenital adrenal hyperplasia: lesions with both adrenocortical and Leydig cell features. Journal of Clinical Endocrinology and Metabolism 2015100 E524-E530. (https://doi.org/10.1210/jc.2014-2036)

18 Engberg H, Butwicka A, Nordenstrom A, Hirschberg AL, Falhammar H, Lichtenstein P, Nordenskjold A, Frisen L \& Landen M. Congenital adrenal hyperplasia and risk for psychiatric disorders in girls and women born between 1915 and 2010: a total population study. Psychoneuroendocrinology 201560 195-205. (https://doi. org/10.1016/j.psyneuen.2015.06.017)

19 Falhammar H \& Torpy DJ. Congenital adrenal hyperplasia due to 21-hydroxylase deficiency presenting as adrenal incidentaloma: a systematic review and meta-analysis. Endocrine Practice 201622 736-752. (https://doi.org/10.4158/EP151085.RA)

20 Nermoen I, Bronstad I, Fougner KJ, Svartberg J, Oksnes M, Husebye ES \& Lovas K. Genetic, anthropometric and metabolic features of adult Norwegian patients with 21-hydroxylase deficiency. European Journal of Endocrinology 2012167 507-516. (https://doi. org/10.1530/EJE-12-0196)

21 Turcu AF \& Auchus RJ. Adrenal steroidogenesis and congenital adrenal hyperplasia. Endocrinology and Metabolism Clinics of North America 201544 275-296. (https://doi.org/10.1016/j. ecl.2015.02.002)

22 Falhammar H \& Thoren M. Clinical outcomes in the management of congenital adrenal hyperplasia. Endocrine 201241 355-373. (https:// doi.org/10.1007/s12020-011-9591-x)

23 Rohle R, Gehrmann K, Szarras-Czapnik M, Claahsen-van der Grinten H, Pienkowski C, Bouvattier C, Cohen-Kettenis P, Nordenstrom A, Thyen U, Kohler B, et al. Participation of adults with disorders/differences of sex development (DSD) in the clinical study dsd-LIFE: design, methodology, recruitment, data quality and study population. BMC Endocrine Disorders 201717 52. (https://doi. org/10.1186/s12902-017-0198-y)

24 Falhammar H, Butwicka A, Landen M, Lichtenstein P, Nordenskjold A, Nordenstrom A \& Frisen L. Increased psychiatric morbidity in men with congenital adrenal hyperplasia due to 21-hydroxylase deficiency. Journal of Clinical Endocrinology and Metabolism 201499 E554-E560. (https://doi.org/10.1210/jc.20133707)

25 Tosson H, Rose SR \& Gartner LA. Description of children with 45,X/46,XY karyotype. European Journal of Pediatrics 2012171 521-529. (https://doi.org/10.1007/s00431-011-1600-9)

26 Frisen L, Nordenstrom A, Falhammar H, Filipsson H, Holmdahl G, Janson PO, Thoren M, Hagenfeldt K, Moller A \& Nordenskjold A. Gender role behavior, sexuality, and psychosocial adaptation in women with congenital adrenal hyperplasia due to CYP21A2 deficiency. Journal of Clinical Endocrinology and Metabolism 200994 3432-3439. (https://doi.org/10.1210/jc.2009-0636)

27 Kathrins M \& Kolon TF. Malignancy in disorders of sex development. Translational Andrology and Urology 20165 794-798. (https://doi. org/10.21037/tau.2016.08.09)

28 Bojesen A, Juul S, Birkebaek NH \& Gravholt CH. Morbidity in Klinefelter syndrome: a Danish register study based on hospital discharge diagnoses. Journal of Clinical Endocrinology and Metabolism 200691 1254-1260. (https://doi.org/10.1210/jc.2005-0697)

29 Falhammar H, Wedell A \& Nordenstrom A. Biochemical and genetic diagnosis of 21-hydroxylase deficiency. Endocrine 201550 306-314. (https://doi.org/10.1007/s12020-015-0731-6)

Received in final form 27 February 2018

Accepted 28 February 2018

Accepted Preprint published online 28 February 2018

\section{http://www.endocrineconnections.org} https://doi.org/10.1530/EC-18-0031 (c) 2018 The authors Published by Bioscientifica Ltd

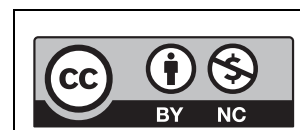

This work is licensed under a Creative Commons Attribution-NonCommercial 4.0 International License. 